\title{
Chemical Characterization of Soils under Floriculture Crops in Selected Villages of Pune and Satara Districts of Maharashtra, India
}

\author{
K.G. Shilpa Shree*, Ganesh B. Kadam, K.S. Girish and K.V. Prasad \\ ICAR- Directorate of Floricultural Research, College of Agriculture Campus, \\ Shivajinagar, Pune, Maharashtra 411 005, India \\ *Corresponding author
}

\begin{tabular}{|c|c|}
\hline & A B S T R A C T \\
\hline & \multirow{6}{*}{$\begin{array}{l}\text { A study was conducted as an attempt to generate farm level data on soil nutrient status of } \\
\text { lands under floricultural crops in Pune and Satara districts of Maharashtra. The chemical } \\
\text { analysis of fifty soil samples collected from Shindawane, Waghapur, Sortapwadi, } \\
\text { Talegaon, Pandegaon, Sasurve and Chiroli villages indicated that soil reaction and salt } \\
\text { concentration were not in harmful range in these soils to support the plant growth except in } \\
\text { few soil samples [highly acidic and highly alkaline pH were observed in Talegaon (one } \\
\text { sample) and Sasurve (one sample) respectively and EC was in harmful range in Talegaon } \\
\text { (one sample), Sortapwadi (two samples) and Waghapur (four samples)]. Soil organic } \\
\text { carbon and available nitrogen status were at alarming status as out of fifty samples none of } \\
\text { the soil samples had sufficient amount of available nitrogen and only } 18 \% \text { of soil samples } \\
\text { were high in organic carbon content. Soil samples analyzed had medium to excess } \\
\text { available phosphorous except for one sample from the village Sasurve which had low } \\
\text { available phosphorous. Available potassium content of the soil samples studied was in } \\
\text { sufficient range in most of the samples. Out of fifty soil samples analyzed } 42 \%, 22 \% \text {, } \\
62 \% \text { and } 54 \% \text { of samples were found deficient in DTPA-extractable Zn, Fe, Mn and Cu } \\
\text { contents respectively and about } 14 \% \text { of samples were deficient in hot water soluble boron } \\
\text { content. }\end{array}$} \\
\hline Keywords & \\
\hline $\begin{array}{l}\text { Soil nutrient status, } \\
\text { Floriculture, Soil } \\
\text { sampling, Chemical } \\
\text { characterization, } \\
\text { Available nutrients. }\end{array}$ & \\
\hline Article Info & \\
\hline $\begin{array}{l}\text { Accepted: } \\
\text { 28 September } 2017 \\
\text { Available Online: } \\
10 \text { October } 2017\end{array}$ & \\
\hline & \\
\hline
\end{tabular}

\section{Introduction}

Generation of information on soil qualities through survey and use of this data in agricultural development planning could augment judicious application of inputs such as chemical fertilizers, amendments and irrigation water which finally leads to maintenance of soil health. Use of plant nutrients according to the actual needs of the soil-crop situations, thereby increasing the productivity can be achieved effectively by addressing the issues at the farm level. This will help in elucidating site-specific soil management options suitable for each land holding. For this, detailed site specific database on soil resources for all the villages of a given state is a prerequisite.

Few pilot studies carried out in various parts of the country have proved conclusively the importance of site specific database for farm planning and the desirability of establishing such a data base at village level for undertaking any farm development work in future (Natarajan et al., 2002). 
Floriculture provides opportunity to farmers to earn a better livelihood and harvest more profit per unit area. Floriculture has received considerable interest in India in recent years from the policymakers, researchers, agricultural and horticultural planners.

The enhancement in per capita income and urbanization has led to increased demand for flowers. A provisional third estimate of National Horticulture Board puts the area under flower crops at 2,43,000 ha with a production of 6,91,000 MT of cut flowers and $15,45,000 \mathrm{MT}$ of loose flowers during 201516. Maharashtra is one of the leading flowers producing states in India. The state has varying soil and agro-climatic conditions, which offer tremendous scope for commercial floriculture. In Maharashtra state, Pune and Satara districts have significant area under open field cultivation and green houses for floriculture.

Plant growth and yield are largely dependent upon the quantities of nutrients that are available in soil. Intensive production of flowers demands adequate levels of fertilization. Improper fertilization, could it be over fertilization or under fertilization can potentially reduce the productivity of flower crops turning floriculture into an uneconomic venture. Data on site specific nutrient status plays a key role in deciding the adequate levels of fertilization. Keeping these points in view, the present study was conducted for generating the soil nutrient status data of farm lands under floriculture crops in selected villages of Pune and Satara districts of Maharashtra.

\section{Materials and Methods}

The study was primarily focused on testing the soil chemical parameters of fifty samples collected from the fields of flower growers in six different villages (Table 1).

\section{Cropping profile}

Chrysanthemum, marigold, aster, rose and tuberose were the major flower crops observed to be cultivated by the farmers in selected villages (Table 1).

\section{Soil sampling}

For soil sampling, V-shaped notch was dug for collecting a uniform $2 \mathrm{~cm}$ thick slice of soil up to a depth of $30 \mathrm{~cm}$. Soil samples were crushed using wooden pestle and mortar, sieved through $2 \mathrm{~mm}$ sieve and stored in properly labeled glass bottles for further analysis.

\section{Soil analysis}

Soil reaction was determined in 1:2.5 ratio of soil: water suspension by potentiometeric method using glass electrode (Jackson, 1973). Electric conductivity was measured in the soil: water (1:2.5) extract using conductivity bridge (Jackson, 1973). Organic carbon was estimated with Walkely and Black rapid titration method as described by Jackson (1973). Available nitrogen was estimated with alkali-permanganate method (Subbaiah and Asija, 1956). The soil samples in acidic range were estimated for phosphorus with Bray's method and the soils in neutral and alkaline range were estimated with Olsen's method. Phosphorus estimation was done by colorimetric estimation by ascorbic acid reductant method using both the extracts (Bray and Kurtz, 1945; Watanabe and Olsen, 1965). Available potassium was extracted with neutral normal ammonium acetate solution and subsequent measurement with atomic absorption spectrophotometer (Jackson, 1973).

Cationic micronutrients viz., iron, copper, manganese and zinc were extracted by DTPA extractant and the concentration was 
measured in atomic absorption spectrophotometer as outlined by Jackson (1973). Available boron was determined using hot water extraction method as given by Berger and Truog (1939) which has been modified by Gupta (1967).

\section{Results and Discussion}

\section{pH and EC}

Soil samples collected from the village Shindawane were alkaline with $\mathrm{pH}$ in the range of 7.85 to 8.2 while the samples from village Talegaon were acidic (5.1 and 6.07). All the soil samples collected from village Pandegaon were neutral in reaction and also soil samples collected from village Waghapur were neutral in reaction except one sample which was alkaline (8.41). Soil samples collected from the village Sortapwadi were neutral to alkaline with $\mathrm{pH}$ in the range of 6.39 to 8.68 while the samples from village Sasurve were neutral to highly alkaline with $\mathrm{pH}$ in the range of 7.19 to 8.70 (Table 2). Among the samples collected, soil $\mathrm{pH}$ ranged from highly acidic (5.1) to highly alkaline (8.7). Out of 50 soil samples, $44 \%$ samples were neutral, $50 \%$ samples were alkaline and only $2 \%$ samples were acidic in reaction.

Soil $\mathrm{pH}$ is a function of nature and concentration of salts in soils and its value would usually indicate the nature of salts present in the soil. Eaton (1950) revealed that the increase in soil $\mathrm{pH}$ was mainly because of presence of relatively higher proportions of soluble bicarbonates and carbonates. The electrical conductivity (EC) of soil is an indirect expression of the total salt concentration in the soil, without reference to the nature and composition of the salts. EC values of soil samples were in the range of 0.154 to $0.32 \mathrm{dS} \mathrm{m}^{-1}, 0.163$ to $1.726 \mathrm{dS} \mathrm{m}^{-1}$, 0.135 to $6.19 \mathrm{dS} \mathrm{m}{ }^{-1}, 0.257$ to $2.27 \mathrm{dS} \mathrm{m}^{-1}$, 0.12 to $0.38 \mathrm{dS} \mathrm{m}^{-1}$ and 0.108 to $0.507 \mathrm{dS} \mathrm{m}^{-1}$ in Shindawane, Waghapur, Sortapwadi,
Talegaon, Pandegaon and Sasurve villages respectively (Table 2). Perusal of EC values of the soil samples indicated that the EC was normal for plant growth in about $86 \%$ of samples and harmful for plant growth in $14 \%$ of samples. The higher EC value suggests that salts would be added to these soils during irrigation and/or fertilizer application. The higher EC values at surface layers might also be due to movement of water from shallow water table to surface layers through capillary force and due to diurnal temperature variations water evaporates leaving behind the salts, which accumulate as encrustations on the soil surface (Deshmukh, 2012).

\section{Soil organic carbon}

Soil organic matter is the major pool of nutrient elements for plant growth. The organic carbon is an indicator of chemical and biological changes taking place in soil and also plays a major role in mineralization and transformation of nutrients in soil (Hebbara et al., 1992). Organic carbon content of soil samples were in the range of 0.42 to $0.87 \%$, 0.44 to $1.49 \%, 0.41$ to $1.14 \%, 0.63$ to 0.68 $\%, 0.10$ to $0.86 \%$ and 0.10 to $0.72 \%$ in Shindawane, Waghapur, Sortapwadi, Talegaon, Pandegaon and Sasurve villages respectively (Table 2). Organic carbon status in soils of Pandegaon, Sasurve, Talegaon and Shindawane was in the range of low to medium. The lower organic matter content in the soils might be attributed to lesser addition of organic residues to soil and also to the prevalence of tropical conditions, where the degradation of organic matter occurs at a faster rate coupled with low vegetation cover, there by leaving less organic $\mathrm{C}$ in the soils. Similar observations were noticed by Nayak et al., (2002). Out of 50 samples, only $18 \%$ of soil samples were high in organic carbon content (Table 5). The high organic carbon status of these soils could be attributed to periodical addition of plant residues, FYM and compost to soil. 


\section{Macronutrients}

It can be realized from the data presented in Table 3 that the soil samples characterized had low to medium level of available nitrogen. The available nitrogen in soils ranged from 156.8 to $250.88 \mathrm{~kg} \mathrm{ha}^{-1}, 219.52$ to $361 \mathrm{~kg} \mathrm{ha}^{-1}, 273.6$ to $376 \mathrm{~kg} \mathrm{ha}^{-1}, 370.32$ to $376.32 \mathrm{~kg} \mathrm{ha}^{-1}, 239.2$ to $371.2 \mathrm{~kg} \mathrm{ha}^{-1}$ and 200.6 to $383.5 \mathrm{~kg} \mathrm{ha}^{-1}$ in Shindawane, Waghapur, Sortapwadi, Talegaon, Pandegaon and Sasurve villages respectively (Table 3 ). Available nitrogen status in the soils of villages Pandegaon and Sasurve was in the range of low to medium while all soil samples from the villages Waghapur, Sortapwadi and Talegaon showed medium available nitrogen. Low to medium soil nutrients status indicates that there will be significant economic response in terms of plant growth and yield to added fertilizers, high nutrient status implies that the soil has sufficient amount of nutrient to support plant growth and there will not be significant economic response in terms of plant growth and yield to added fertilizers. Out of fifty samples analyzed none of the soil samples had sufficient amount of available nitrogen (Table 5). Since flowers are harvested periodically as and when they bloom, the available nitrogen might have been utilized by the standing crop continuously to support further growth and flower production. This rapid and continuous removal of available nitrogen by the crop coupled with other possible nitrogen losses like leaching and volatilization might have resulted in lower available nitrogen status of these soils. Lower available nitrogen in soils might also be due to lower organic carbon status and poor physical conditions of the soil which might have accentuated the losses of soil nitrogen due to denitrification and volatilization losses. Lower available nitrogen in soils having higher $\mathrm{pH}$ as observed in Shindawane (sample no 1), Chiroli (sample no 40) and Sasurve (sample no 43, 47 and 50) might be due to volatilization losses of nitrogen in the soils (Jenny and Raychaudhuri, 1960) and also due to reduction of nitrogen fixation by microorganisms.

The soil samples analyzed had medium to excess available phosphorous except for one sample from the village Sasurve which was low in available phosphorous (13.14 $\mathrm{kg} \mathrm{ha}^{-1}$ ) (Table 3). Available phosphorous in soils ranged from 31.29 to $58.11 \mathrm{~kg} \mathrm{ha}^{-1}$, 43.85 to $89.5 \mathrm{~kg} \mathrm{ha}^{-1}, 30.88$ to $95.34 \mathrm{~kg} \mathrm{ha}^{-1}, 86.3$ to $112.5 \mathrm{~kg} \mathrm{ha}^{-1}, 15.85$ to $62.98 \mathrm{~kg} \mathrm{ha}^{-1}$ and 13.41 to $64.61 \mathrm{~kg} \mathrm{ha}^{-1}$ in Shindawane, Waghapur, Sortapwadi, Talegaon, Pandegaon and Sasurve villages respectively (Table 3). Available phosphorous status in the soils of villages Pandegaon ranged from low to medium, of the village Sasurve ranged from low to excess, while all soil samples from the villages Sortapwadi, Waghapur, Shindawane and Talegaon were in the range of high to excess. Out of 50 samples, $72 \%$ of soil samples had excess amount of available phosphorous (Table 5). The higher phosphorus content of soil could be due to lesser precipitation of added phosphorus as calcium and magnesium phosphate and due to acidulation and solubility of fixed phosphorus.

The available potassium content in soil samples was in the range of 254.1 to 279.46 $\mathrm{kg} \mathrm{ha}^{-1}, 224.98$ to $301.19 \mathrm{~kg} \mathrm{ha}^{-1}, 235.62$ to $492.82 \mathrm{~kg} \mathrm{ha}^{-1}, 391.53$ to $393.78 \mathrm{~kg} \mathrm{ha}^{-1}$, 41.44 to $189.84 \mathrm{~kg} \mathrm{ha}^{-1}$ and 103.60 to 479.92 $\mathrm{kg} \mathrm{ha} \mathrm{ha}^{-1}$ in Shindawane, Waghapur, Sortapwadi, Talegaon, Pandegaon and Sasurve villages respectively (Table 3). All soil samples from the villages Sortapwadi and Waghapur were in the range of medium to excess while soil samples from the village Pandegaon were in the range of low to medium (41.44 to $197.68 \mathrm{~kg} \mathrm{ha}^{-1}$ ) in available potassium content. 
Table.1 Details of soil samples collected from selected villages of Pune and Satara districts

\begin{tabular}{|l|l|l|l|c|}
\hline Name of village & Taluk & Major flower crops grown & District & Number of soil Samples collected \\
\hline Shindawane & Haveli & Aster, Rose, Tuberose, Chrysanthemum & Pune & 3 \\
\hline Waghapur & Purandar & Rose, Chrysanthemum, Marigold & Pune & 11 \\
\hline Sortapwadi & Haveli & Marigold, Aster, Rose, Chrysanthemum & Pune & 17 \\
\hline Talegaon & Maval & Rose, Marigold, Tuberose, Aster & Pune & 2 \\
\hline Pandegaon & Bhor & Chrysanthemum, Marigold & Pune & 6 \\
\hline Chiroli & Haveli & Marigold, Aster, Rose, Chrysanthemum & Pune & 1 \\
\hline Sasurve & Koregaon & Tuberose, Aster, Chrysanthemum & Satara & 10 \\
\hline \multicolumn{7}{|l|}{ Total number of soil samples } & \\
\hline
\end{tabular}

Table.2 Soil reaction ( $\mathrm{pH}$ ), electrical conductivity (EC) and organic carbon (OC) status of soil samples collected from selected villages of Pune and Satara districts

\begin{tabular}{|c|c|c|c|c|}
\hline Village & Sample no. & pH & $E C\left(d S ~ m^{-1}\right)$ & OC (\%) \\
\hline \multirow{3}{*}{ Shindawane } & 1 & 8.20 & 0.320 & 0.42 \\
\hline & 2 & 8.15 & 0.285 & 0.87 \\
\hline & 3 & 7.85 & 0.154 & 0.60 \\
\hline \multirow{11}{*}{ Waghapur } & 4 & 7.57 & 0.358 & 0.36 \\
\hline & 5 & 6.92 & 0.761 & 1.17 \\
\hline & 6 & 7.26 & 1.205 & 0.74 \\
\hline & 7 & 7.42 & 0.463 & 0.44 \\
\hline & 8 & 7.24 & 0.378 & 0.48 \\
\hline & 9 & 6.79 & 1.588 & 1.49 \\
\hline & 10 & 7.08 & 1.785 & 0.44 \\
\hline & 11 & 8.41 & 0.163 & 0.41 \\
\hline & 12 & 7.32 & 0.931 & 0.62 \\
\hline & 13 & 6.99 & 0.567 & 1.26 \\
\hline & 14 & 7.31 & 1.726 & 1.29 \\
\hline \multirow{17}{*}{ Sortapwadi } & 15 & 6.39 & 3.920 & 1.31 \\
\hline & 16 & 7.41 & 0.494 & 0.69 \\
\hline & 17 & 8.05 & 0.522 & 0.41 \\
\hline & 18 & 8.04 & 0.641 & 0.77 \\
\hline & 19 & 8.08 & 0.542 & 0.62 \\
\hline & 20 & 8.05 & 0.401 & 1.05 \\
\hline & 21 & 8.12 & 0.654 & 0.29 \\
\hline & 22 & 8.03 & 0.697 & 1.25 \\
\hline & 23 & 8.14 & 0.372 & 1.20 \\
\hline & 24 & 8.15 & 0.588 & 0.81 \\
\hline & 25 & 8.23 & 0.378 & 1.14 \\
\hline & 26 & 7.53 & 0.753 & 0.71 \\
\hline & 27 & 8.68 & 0.291 & 0.54 \\
\hline & 28 & 8.09 & 0.135 & 0.68 \\
\hline & 29 & 8.64 & 6.190 & 0.77 \\
\hline & 30 & 6.77 & 0.396 & 0.83 \\
\hline & 31 & 6.84 & 0.689 & 0.75 \\
\hline \multirow[b]{2}{*}{ Talegaon } & 32 & 6.07 & 2.270 & 0.68 \\
\hline & 33 & 5.10 & 0.257 & 0.63 \\
\hline \multirow{6}{*}{ Pandegaon } & 34 & 6.57 & 0.382 & 0.86 \\
\hline & 35 & 6.66 & 0.234 & 0.24 \\
\hline & 36 & 6.83 & 0.120 & 0.54 \\
\hline & 37 & 7.00 & 0.320 & 0.59 \\
\hline & 38 & 6.80 & 0.105 & 0.78 \\
\hline & 39 & 6.81 & 0.168 & 0.10 \\
\hline Chiroli & 40 & 8.15 & 0.634 & 0.20 \\
\hline \multirow{10}{*}{ Sasurve } & 41 & 7.82 & 0.217 & 0.10 \\
\hline & 42 & 7.19 & 0.108 & 0.15 \\
\hline & 43 & 8.50 & 0.241 & 0.33 \\
\hline & 44 & 8.70 & 0.298 & 0.60 \\
\hline & 45 & 7.95 & 0.288 & 0.38 \\
\hline & 46 & 7.60 & 0.112 & 0.10 \\
\hline & 47 & 8.13 & 0.215 & 0.10 \\
\hline & 48 & 8.20 & 0.507 & 0.72 \\
\hline & 49 & 7.94 & 0.308 & 0.20 \\
\hline & 50 & 8.45 & 0.251 & 0.23 \\
\hline
\end{tabular}


Table.3 Major nutrient status of soil samples collected from selected villages of Pune and Satara districts

\begin{tabular}{|c|c|c|c|c|}
\hline Village & Sample no. & $\mathbf{N}\left(\mathrm{kg} \mathrm{ha}^{-1}\right)$ & $P\left(\mathrm{~kg} \mathrm{ha}^{-1}\right)$ & $K\left(\mathrm{~kg} \mathrm{ha}^{-1}\right)$ \\
\hline \multirow{3}{*}{ Shindawane } & 1 & 156.80 & 58.11 & 279.46 \\
\hline & 2 & 214.21 & 31.29 & 256.11 \\
\hline & 3 & 250.88 & 40.23 & 254.10 \\
\hline \multirow{11}{*}{ Waghapur } & 4 & 251.31 & 82.42 & 254.43 \\
\hline & 5 & 219.52 & 43.85 & 271.79 \\
\hline & 6 & 247.56 & 76.39 & 246.59 \\
\hline & 7 & 282.24 & 80.83 & 327.29 \\
\hline & 8 & 286.20 & 58.90 & 287.53 \\
\hline & 9 & 292.40 & 84.22 & 301.19 \\
\hline & 10 & 292.33 & 74.70 & 318.27 \\
\hline & 11 & 313.60 & 48.36 & 224.98 \\
\hline & 12 & 318.20 & 77.61 & 245.70 \\
\hline & 13 & 361.00 & 89.50 & 283.94 \\
\hline & 14 & 339.50 & 81.80 & 286.63 \\
\hline \multirow{17}{*}{ Sortapwadi } & 15 & 354.20 & 95.34 & 452.11 \\
\hline & 16 & 313.60 & 79.24 & 492.82 \\
\hline & 17 & 301.20 & 65.02 & 333.73 \\
\hline & 18 & 311.00 & 62.58 & 281.20 \\
\hline & 19 & 313.60 & 63.80 & 293.18 \\
\hline & 20 & 363.90 & 65.83 & 260.03 \\
\hline & 21 & 273.60 & 66.24 & 279.02 \\
\hline & 22 & 382.00 & 58.92 & 278.68 \\
\hline & 23 & 368.00 & 64.61 & 255.05 \\
\hline & 24 & 304.69 & 58.51 & 251.58 \\
\hline & 25 & 344.96 & 76.80 & 294.08 \\
\hline & 26 & 300.50 & 91.75 & 305.56 \\
\hline & 27 & 354.90 & 30.88 & 236.96 \\
\hline & 28 & 371.20 & 59.73 & 247.88 \\
\hline & 29 & 366.10 & 44.29 & 235.62 \\
\hline & 30 & 376.00 & 91.18 & 392.47 \\
\hline & 31 & 358.10 & 71.81 & 359.56 \\
\hline \multirow[b]{2}{*}{ Talegaon } & 32 & 376.32 & 86.30 & 391.53 \\
\hline & 33 & 370.32 & 112.50 & 393.78 \\
\hline \multirow{6}{*}{ Pandegaon } & 34 & 371.20 & 62.98 & 189.84 \\
\hline & 35 & 277.60 & 19.91 & 41.44 \\
\hline & 36 & 307.68 & 15.85 & 107.52 \\
\hline & 37 & 311.20 & 49.17 & 150.08 \\
\hline & 38 & 339.04 & 22.35 & 122.08 \\
\hline & 39 & 239.20 & 26.82 & 138.88 \\
\hline Chiroli & 40 & 241.80 & 47.95 & 418.00 \\
\hline \multirow{10}{*}{ Sasurve } & 41 & 250.10 & 32.91 & 197.68 \\
\hline & 42 & 247.60 & 13.41 & 105.28 \\
\hline & 43 & 217.20 & 20.32 & 103.60 \\
\hline & 44 & 370.60 & 64.61 & 386.10 \\
\hline & 45 & 301.30 & 31.70 & 332.70 \\
\hline & 46 & 201.76 & 43.07 & 401.12 \\
\hline & 47 & 200.60 & 18.29 & 119.84 \\
\hline & 48 & 383.50 & 18.69 & 479.92 \\
\hline & 49 & 246.80 & 23.97 & 421.90 \\
\hline & 50 & 227.20 & 34.95 & 448.00 \\
\hline
\end{tabular}


Table.4 Micronutrients status of soil samples collected from selected villages of Pune and Satara districts

\begin{tabular}{|c|c|c|c|c|c|c|}
\hline Village & $\begin{array}{c}\text { Sample } \\
\text { no. }\end{array}$ & $\begin{array}{c}\mathbf{Z n} \\
(\mathbf{p p m})\end{array}$ & $\begin{array}{c}\text { Mn } \\
\text { (ppm) }\end{array}$ & $\begin{array}{c}\mathbf{C u} \\
(\mathbf{p p m})\end{array}$ & $\begin{array}{c}\mathbf{F e} \\
(\mathbf{p p m})\end{array}$ & $\begin{array}{c}\text { B } \\
(\mathbf{p p m})\end{array}$ \\
\hline \multirow{3}{*}{ Shindawane } & 1 & 0.52 & 1.49 & 0.17 & 2.16 & 1.11 \\
\hline & 2 & 0.56 & 1.27 & 0.19 & 2.17 & 1.17 \\
\hline & 3 & 0.64 & 1.23 & 0.21 & 4.34 & 1.05 \\
\hline \multirow{11}{*}{ Waghapur } & 4 & 0.63 & 1.25 & 0.21 & 4.34 & 0.90 \\
\hline & 5 & 1.54 & 0.91 & 0.69 & 3.86 & 0.52 \\
\hline & 6 & 0.87 & 0.73 & 0.49 & 3.10 & 0.77 \\
\hline & 7 & 0.68 & 1.05 & 0.23 & 3.72 & 0.51 \\
\hline & 8 & 0.62 & 1.96 & 0.42 & 4.21 & 0.49 \\
\hline & 9 & 0.69 & 4.62 & 0.77 & 4.58 & 0.54 \\
\hline & 10 & 0.67 & 2.79 & 0.68 & 4.95 & 1.72 \\
\hline & 11 & 0.52 & 0.93 & 0.15 & 2.02 & 0.46 \\
\hline & 12 & 0.71 & 2.10 & 0.53 & 3.52 & 0.39 \\
\hline & 13 & 0.67 & 3.32 & 0.61 & 6.47 & 0.80 \\
\hline & 14 & 0.62 & 2.11 & 0.41 & 4.71 & 0.56 \\
\hline \multirow{17}{*}{ Sortapwadi } & 15 & 0.81 & 4.65 & 0.98 & 15.44 & 0.76 \\
\hline & 16 & 0.86 & 3.45 & 0.63 & 12.19 & 0.72 \\
\hline & 17 & 0.37 & 1.40 & 0.13 & 3.54 & 0.90 \\
\hline & 18 & 0.43 & 1.59 & 0.16 & 2.44 & 0.96 \\
\hline & 19 & 0.58 & 1.70 & 0.18 & 2.09 & 0.82 \\
\hline & 20 & 0.50 & 1.82 & 0.15 & 4.16 & 0.74 \\
\hline & 21 & 0.42 & 1.25 & 0.09 & 2.29 & 0.92 \\
\hline & 22 & 0.56 & 1.65 & 0.13 & 2.99 & 0.85 \\
\hline & 23 & 0.62 & 1.46 & 0.06 & 2.97 & 0.88 \\
\hline & 24 & 0.56 & 1.20 & 0.09 & 2.49 & 0.90 \\
\hline & 25 & 0.45 & 0.77 & 0.06 & 2.57 & 1.10 \\
\hline & 26 & 0.85 & 2.01 & 0.14 & 5.02 & 0.80 \\
\hline & 27 & 0.20 & 0.17 & 0.04 & 4.35 & 1.77 \\
\hline & 28 & 0.22 & 0.42 & 0.06 & 4.40 & 1.18 \\
\hline & 29 & 0.23 & 0.80 & 0.04 & 2.91 & 2.88 \\
\hline & 30 & 0.91 & 2.05 & 0.14 & 6.09 & 0.48 \\
\hline & 31 & 0.79 & 2.15 & 0.19 & 16.39 & 0.51 \\
\hline \multirow[b]{2}{*}{ Talegaon } & 32 & 1.76 & 15.00 & 4.78 & 44.39 & 0.44 \\
\hline & 33 & 2.80 & 28.15 & 6.63 & 85.64 & 0.31 \\
\hline \multirow{6}{*}{ Pandegaon } & 34 & 0.96 & 2.85 & 0.82 & 25.43 & 0.56 \\
\hline & 35 & 1.07 & 2.17 & 0.62 & 20.83 & 0.66 \\
\hline & 36 & 0.71 & 2.43 & 0.52 & 16.35 & 0.69 \\
\hline & 37 & 1.75 & 2.23 & 0.96 & 17.31 & 0.64 \\
\hline & 38 & 0.93 & 2.55 & 1.40 & 21.61 & 0.51 \\
\hline & 39 & 1.09 & 2.17 & 1.50 & 20.37 & 0.48 \\
\hline Chiroli & 40 & 0.37 & 1.60 & 0.15 & 3.87 & 1.50 \\
\hline \multirow{10}{*}{ Sasurve } & 41 & 0.63 & 1.33 & 0.34 & 4.37 & 0.72 \\
\hline & 42 & 0.91 & 1.45 & 0.52 & 26.01 & 0.64 \\
\hline & 43 & 0.23 & 0.31 & 0.18 & 1.79 & 2.88 \\
\hline & 44 & 0.15 & 0.11 & 0.14 & 1.47 & 3.41 \\
\hline & 45 & 0.40 & 1.13 & 0.23 & 4.99 & 1.87 \\
\hline & 46 & 0.61 & 1.37 & 0.26 & 6.55 & 1.43 \\
\hline & 47 & 0.37 & 0.99 & 0.16 & 3.99 & 1.56 \\
\hline & 48 & 0.51 & 0.93 & 0.09 & 2.07 & 2.00 \\
\hline & 49 & 0.79 & 0.89 & 0.12 & 3.10 & 1.45 \\
\hline & 50 & 0.16 & 1.11 & 0.17 & 2.79 & 1.87 \\
\hline
\end{tabular}


Table.5 Proportion of soil samples of selected villages of Pune and Satara districts falling under different soil fertility ratings of major nutrients

\begin{tabular}{|l|c|c|c|c|}
\hline \multirow{2}{*}{$\begin{array}{l}\text { Chemical } \\
\text { parameter }\end{array}$} & \multicolumn{4}{|c|}{ Ratings } \\
\cline { 2 - 5 } & \% Low & \% Medium & \% High & \% Excess \\
\hline OC & 38 & 44 & 18 & ------ \\
\hline $\mathrm{N}$ & 32 & 68 & ------- & ------ \\
\hline $\mathrm{P}$ & 2 & 16 & 10 & 72 \\
\hline $\mathrm{K}$ & 16 & 22 & 26 & 36 \\
\hline
\end{tabular}

Higher available potassium content in soils might be due to regular addition through fertilizers and occurrence of potash-rich micaceous and feldspar minerals in the soils whereas lower available potassium content could be attributed to depletion of potassium content during crop cultivation without proper periodical replenishment.

Low value flower crops like marigold and chrysanthemum were mostly being cultivated in traditional way without giving much importance to balanced fertilization. Often urea and some quantities of farm yard manure were applied as the major source of nutrients to these crops resulting in low phosphorous and potassium content in soil (Pandegaon). But when farmers grow high value flower crops like rose and tuberose, they possibly give importance to balanced fertilization including the application of phosphorous and potassium fertilizers. This periodical and balanced fertilization might have lead to some elevated levels of nutrients in soil (High to excess phosphorous in Sortapwadi, Waghapur, Shindawane and Talegaon and medium to excess potassium in Sortapwadi and Waghapur that grow rose and tuberose).

\section{Micronutrients}

DTPA-extractable $\mathrm{Zn}$ content was in the range of 0.52-0.64 ppm, 0.52-1.54 ppm, 0.20.91 ppm, 1.76-2.8 ppm, 0.71-1.75 ppm, 0.370.91 and 0.37 ppm in Shindawane, Waghapur, Sortapwadi, Talegaon, Pandegaon, Sasurve and Chiroli villages respectively. DTPAextractable Mn content was in the range of 1.27 to $1.49 \mathrm{ppm}, 0.73$ to $4.62 \mathrm{ppm}, 0.17$ to $4.65 \mathrm{ppm}, 15$ to $28.15 \mathrm{ppm}, 2.17$ to $2.85 \mathrm{ppm}$, 0.11 to $1.33 \mathrm{ppm}$ and $1.6 \mathrm{ppm}$ in Shindawane, Waghapur, Sortapwadi, Talegaon, Pandegaon, Sasurve and Chiroli villages respectively. DTPA-extractable $\mathrm{Cu}$ content was in the range of 0.11 to $0.17 \mathrm{ppm}, 0.15$ to $0.69 \mathrm{ppm}$, 0.04 to $0.98 \mathrm{ppm}, 4.78$ to $6.63 \mathrm{ppm}, 0.52$ to $1.50 \mathrm{ppm}, 0.09$ to $0.52 \mathrm{ppm}$ and $0.15 \mathrm{ppm}$ in Shindawane, Waghapur, Sortapwadi, Talegaon, Pandegaon, Sasurve and Chiroli villages respectively.

The critical limits of micronutrients followed for interpretation in the present study were 0.6 ppm, 0.2-2 ppm, 2.5-4.5 ppm, 2 ppm and 0.5 ppm for $\mathrm{Zn}, \mathrm{Cu}, \mathrm{Fe}, \mathrm{Mn}$ and $\mathrm{B}$ respectively. Out of fifty soil samples analyzed $42 \%, 22$ $\%, 62 \%$ and $54 \%$ of samples were found deficient in DTPA-extractable $\mathrm{Zn}, \mathrm{Fe}, \mathrm{Mn}$ and $\mathrm{Cu}$ contents (Table 4). Lower micronutrients status observed in soils of Shindawane (sample number 1 and 2), Waghapur (sample number 11), Sortapwadi (sample number 17, 18, 19 and 24), Sasurve (sample number 42 and 43) and Chiroli (sample number 40) might be due to high $\mathrm{pH}$ and low organic matter which might have resulted in the formation of insoluble compounds of micronutrients. The higher concentrations of micronutrients observed in soil samples of Waghapur (sample number 8, 9 and 10), Sortapwadi (sample number 15 and 16), Talegaon (32 and 33) and Pandegaon (sample 
number $34,35,36,37,38$ and 39) might be due to low $\mathrm{pH}$ coupled with higher biological activity and chelation of organic compounds released during the decomposition of organic matter left after harvesting of crop (Verma $e t$ al., 2005). Noticeably high concentrations of $\mathrm{Fe}, \mathrm{Mn}, \mathrm{Cu}$ and $\mathrm{Zn}$ in Talegaon could be attributed to highly acidic $\mathrm{pH}$ and regular application of micronutrients to rose and tuberose that were grown in that village. Hot water soluble boron in the soil samples was in the range of 1.05 to $1.17 \mathrm{ppm}, 0.39$ to 1.72 ppm, 0.48 to $2.88 \mathrm{ppm}, 0.31$ to $0.44 \mathrm{ppm}$, 0.48 to $0.69 \mathrm{ppm}, 0.64$ to $3.41 \mathrm{ppm}$ and 1.5 ppm in Shindawane, Waghapur, Sortapwadi, Talegaon, Pandegaon, Sasurve and Chiroli villages respectively (Table 4). Higher concentration of boron observed in most of the soil samples (Shindawane, Sortapwadi, Chiroli and Sasurve) could be attributed to alkaline $\mathrm{pH}$ and limited leaching. Soil samples of Waghapur (sample no 7, 8, 11, 12 and 14), Sortapwadi (sample no 30 and 31), Talegaon (sample no 32 and 33) and Pandegaon (sample no 39) were observed to be boron deficient due to non-alkaline $\mathrm{pH}$.

Chemical analysis of the soil samples collected from Shindawane, Waghapur, Sortapwadi, Talegaon, Pandegaon, Sasurve and Chiroli villages indicated that the soil reaction $(\mathrm{pH})$ and salt concentration (EC) were in safe range to support the plant growth in most of the soil samples. But the organic carbon and available nitrogen status of these soils were low in most of the samples.

Available phosphorous and potassium content of the soil samples studied were in sufficient range in most of the soil samples. Among micronutrients, manganese was observed to be the most deficient one followed by copper, zinc, boron and iron. The soil micronutrients status has to be monitored periodically as significant number of soil samples were found deficient in these available micronutrients.

\section{Acknowledgement}

The authors express gratitude to the Director, ICAR- NRCG for extending the facilities in conducting the present investigation. The guidance and technical advise obtained from Dr. A.K. Upadhyay, PS, ICAR- NRC Grapes is duly acknowledged.

\section{References}

Berger, K.C., and Truog, E. 1939. Boron determination in soils and plants. Ind. Eng. Chem. II. 11, 540-545.

Bray, R.H., and Kurtz, L.T. 1945. Determination of total, organic and available forms of phosphorous in soils. Soil Sci. 59, 39-45.

Deshmukh, K. K., 2012. Studies on chemical characteristics and classification of soils from Sangamner area, Ahmednagar district, Maharashtra, India. Rasayan J. Chem. 5(1), 154-162.

Eaton, E. M., 1950. Significance of carbonates in irrigation waters. Soil Sci. 69: 123-133.

Gupta, U. C., 1967. A simplified method for determining the hot water soluble boron in podzol soils. Soil Sci. 103, 424-428.

Hebbara, M., Viswanath, D. P., and Devarnawadgi, S. B. 1992. Performance of tree species on marginally saline vertisols of Tungabhadra project area. $J$. Indian Soc. Soil Sci. 40, 616-617.

Jackson, M.L., 1973. Soil chemical analysis. Prentice hall of India (pvt) Ltd., New Delhi.

Jenny, H., and Raychaudhuri, S. P. 1960. Effect of climate and cultivation on nitrogen and organic carbon reserves in Indian soils. Indian Council of Agricultural Research, New Delhi, pp. 28-72.

Natarajan, A., Krishnan, P. Velayutham, M and Gajbhieye, K.S. 2002. Land Resources of Kudankulam, Vijayapati 
and Erukkandurai villages, Radhapuram taluk, Tirunelveli district. NBSS\&LUP, Nagpur.

Nayak, D. C., Sarkar, D. and Das, K. 2002. Forms and distribution of pedogenic iron, aluminium and manganese in some Benchmark soils of West Bengal. $J$. Indian. Soc. Soil Sci. 50, 89-93.

Subbaih B.V., and Asija, G.L. 1956. A rapid procedure for the determination of available nitrogen in soils. Curr. Sci. 25, 259-260.
Verma, V. K., Setia, R. K., Sharma, P. K., Charanjit Singh and Ashok kumar. 2005. Micronutrient distribution in soils developed on different physiographic units of Fatehgarh Sahib District of Punjab. Agropedology 15, 70-75.

Watanabe, F.S., and Olsen, S.R. 1965. Test of ascorbic acid methods for determining phosphorous in water and sodium bicarbonate extracts of soil. Soil Sci. Soc. Am. Proc. 29, 677-678.

\section{How to cite this article:}

Shilpa Shree, K.G., Ganesh B. Kadam, K.S. Girish and Prasad, K.V. 2017. Chemical Characterization of Soils under Floriculture Crops in Selected Villages of Pune and Satara Districts of Maharashtra. Int.J.Curr.Microbiol.App.Sci. 6(10): 3574-3583.

doi: https://doi.org/10.20546/ijcmas.2017.610.421 